\title{
How a Flexible Teaching "Camp" Answered Our Pandemic Teaching Emergency
}

\section{Patricia Dinneen}

\begin{abstract}
At the start of the COVID-19 pandemic, faculty scrambled to move courses online and to master technology tools seemingly overnight. Keeping a focus on course design and teaching techniques became a central challenge for a center for teaching and learning (CTL) in the midst of the emergency move to online and blended learning. This article chronicles one CTL's design and implementation of a virtual Forward Looking Explorations in Teaching Camp (FLEX Camp) that aimed to address pedagogy and technology simultaneously by immersing faculty in learning experiences. It details the planning process, learning goals, key activities, assessment methods, and lessons learned from the FLEX Camp approach.
\end{abstract}

Keywords: experiential, educational development, flexible, online

As a center for teaching and learning (CTL) that has always been closely aligned with technology and online teaching units, we recognized the COVID-19 pandemic emergency as an opportunity to test an experiential approach to educational development online. This is a model that we have long believed in, despite not previously having the opportunity to try it at scale. It was also an opportunity to draw attention to inclusive teaching and student motivation practices. How- 
ever, we knew from experience that keeping principles of course design and pedagogy front and center in the midst of a pandemic could be a challenge when faculty already had concerns about implementing and mastering technology.

In the earliest days of the COVID-19 pandemic, during March and April 2020, concerns about technology dominated, and our colleagues in instructional technology and IT services shouldered the burden for faculty support. Faculty, leadership, and staff were laser-focused on logistical concerns: Would the connectivity of the learning management system (LMS) hold up to unprecedented demand? How does a synchronous class space work? What about discussion, testing, and grading tools? In the midst of these heightened concerns, our CTL lacked an opening to present course design and pedagogical approaches we knew could help.

Then, in May, as the initial panic eased and it was clear that virtual learning would continue, concern for teaching emerged. Faculty who had cobbled together a virtual end to their spring semester wanted to feel more in control of their courses. They asked to learn about synchronous and asynchronous online teaching practices and what a blend of online and in-person learning could look like. Students, too, were clamoring for better online learning experiences. Suddenly, our small CTL was called upon as never before to provide support for virtual and blended teaching - and to provide this support by June with only a few weeks to prepare. Additionally, social justice protests and the 2020 presidential election were heating up. Faculty sought guidance on how to lead difficult conversations and ways to create community online in order to address this confluence of challenges.

Our CTL had what change management experts term a burning platform (Kaplan, 2020), an opportunity to create change due to an emergency situation. As a small team, we had to focus our efforts on a program that we could scale. What evolved as the centerpiece of our effort was our Forward Looking Explorations in Teaching Camp, or simply FLEX Camp. FLEX Camp was a 2.5-day online program that guided a cohort of faculty through a range of experiences with teach- 
ing topics and tools. In total, from early June through mid-August, we delivered seven camps to over 250 faculty from across the university. Because of the very positive response over the summer, we have been asked to deliver additional FLEX Camps for our spring 2021 semester. Our FLEX Camp experiences have also led to more flexibility in our programming overall.

This compilation of experiences during FLEX Camp constitutes what we refer to as experiential online faculty development. The term draws from Kolb's (1984) theory of experiential learning that describes learning as a process whereby knowledge is created through the transformation of experience. In experiential learning, knowledge results from the combinations of grasping and transforming the experience. This article describes our CTL context, FLEX Camp effort, and lessons learned.

\section{Background: Our CTL Context}

The George Washington University is a level 1 research university located in Washington, DC. As an urban campus, restrictions due to the COVID-19 pandemic have been extensive. For instance, in early summer 2020, we had to abandon our plans-to use a hybrid teaching model and reopen the campus for the upcoming fall semesterbecause there was insufficient space to social distance, as recommended by the Centers for Disease Control and Prevention.

Our CTL unit was reorganized about two years ago to more closely align with the university's central instructional technology lab and team of instructional designers. We are a staff of two-a director of faculty development and an educational director. We both happen to have backgrounds in online learning and in providing technology support, which was a great help in navigating the new teaching landscape. A dedicated group of faculty members inform our work through an advisory board. Our programming is open to faculty from across the university. 
In recent years, our unit had been able to increase awareness of learning-focused design and scholarship of teaching and learning, particularly in the face-to-face classroom, through a Course Design Institute (CDI) and through a teaching program for early career faculty. Our $\mathrm{CDI}$ was modeled after the work of Michael Palmer and colleagues at the University of Virginia's Center for Teaching Excellence. These efforts honed our understanding of experiential learning in the physical classroom, which would lead to activities that we could move online for FLEX Camp.

Before the pandemic, we had started to deliver some workshops online. In 2018, we developed a self-paced Online Faculty Development course that faculty could take within the LMS, with the dual goal of providing experience with the platform and teaching about course design. The asynchronous course was sparsely used. However, it provided us with a ready-made platform within the LMS to host FLEX Camp.

For FLEX Camp, we collaborated with two instructional designers. They, too, had diverse backgrounds, with one holding a doctorate in education and the other having extensive experience as an online student. The crossover experiences helped us plan and deliver the camp program in tandem.

\section{FLEX Camp Program}

The FLEX Camp was developed as a way to accommodate many faculty members quickly in a program that we could repeat and repurpose over an entire summer. We based the program on early feedback from faculty and students and our experiences moving our annual CDI online.

\section{Planning Process}

Early in the pandemic emergency, we were invited to virtual listening sessions with students and faculty. We learned that students' biggest concern was making sure they could get help from their faculty at a 
distance. Faculty were primarily concerned with managing the technology and, also, with maintaining connection and a sense of community with their students. Both groups were concerned about the social and political issues emerging rapidly in spring 2020.

In response to this direct input, we adapted our thinking about our CTL programming in three major ways. First, we changed our overarching goal from transforming courses to adapting courses. We knew from previous work on faculty attitudes regarding changing course design (Dinneen, 2016) that significant change typically faced considerable resistance that took sustained effort to overcome (Dancy \& Henderson, 2012). In the midst of a teaching emergency, we did not think it wise to try to convince faculty that they needed to make extensive changes to their course when adapting would be an important, and likely sufficient, step. Instead, we decided to help faculty analyze their key learning experiences and assignments in order to identify what could be kept, altered, or eliminated for an online experience.

Second, we embraced educating faculty about technology tools. For years, in order to reinforce with faculty that our CTL focused on course and teaching approaches, we distanced ourselves from discussing technology. To distinguish educational development from instructional design, we steered clear of online learning and focused on the physical classroom. However, this strategy would no longer work as learning technologies became so central to course implementation.

Third, we took more risk. Given just a few weeks to deliver our CDI online and then pivot to our first FLEX Camp, we had to jump into our efforts without much background research or pilot testing. We used our experience in instructional design and with moving our CDI to a virtual format to inform pacing and the balance between synchronous and asynchronous work in FLEX Camp. We knew that courses would be fully online at some point, even if they started out in a hybrid mode, so we planned a program that focused on the approaches that would work regardless of modality.

Three conceptual frameworks formed the backdrop for our plan- 
ning. One was Fink's (2003) taxonomy of significant learning, which presents cognitive and affective aspects of learning. The second was the technological pedagogical content knowledge (TPACK) model for instructional technology (Koehler, 2011; Rodgers, 2018). It expands Lee Shulman's framework for pedagogical content knowledge (PCK) from the 1980s (Hashweh, 2014) to include knowledge about technology. Third, Schein's (1996) unfreeze, change, and refreeze theory of learning led us to focus on ways to help faculty reflect on previous beliefs and teaching approaches in order to move to new practices.

\section{Establishing Program Goals}

Our learning goals for FLEX Camp reflected what we believed were most important for faculty to know or be able to do, especially the many who were new to online learning:

- Visualize the online classroom space and active learning possibilities. Many faculty were thrown into online teaching with little to no experience as a student or instructor in that space, so they were being asked to function in a foreign landscape.

- Implement strategies to support student motivation and engagement within the online context. Faculty wanted to move active learning to the online space but needed ideas and examples of what could work.

- Create content, especially recorded lecture segments. We wanted faculty to feel comfortable using the simple tools now available to create their own original content for courses.

- Focus on a solid assessment strategy. We saw faculty be consumed by concerns over how to deliver their synchronous class session and thought it was important to redirect attention to where students would concentrate their efforts-the assigned work.

- Design a clear, easy-to-navigate, and accessible course structure in the learning management system.

To Improve the Academy • Vol. 39, No. 3• Spring 2021 
- Know how to get help with technology and teaching in order to feel supported after FLEX Camp.

\section{Topics and Sessions}

Camp was organized around five, 2-hour synchronous sessions. Days 1 and 2 included morning and afternoon sessions with a 2-hour break when our teaching team invited individual questions and course consultations. We also stayed online for additional consultations from 3:00 p.m. to 5:00 p.m. Finally, Day 3 was a half-day, with a single morning session and consultation time.

We designed and co-taught FLEX Camp in collaboration with our two instructional design colleagues. Partners in the instructional technology lab provided backup help when faculty experienced difficulties connecting in the LMS. We offered to provide a letter of completion for attendance and submission of a partially completed ( 2 to 3 weeks planned) Course Planning Template as incentive to attend the whole program.

We present the breakdown of session topics and activities in Table 1. Throughout, we introduced tools that we thought would be most useful for faculty to use in their own courses.

\section{Combining Tools and Teaching Techniques: Examples of Key Activities}

We introduced a number of active learning techniques by engaging faculty with technology tools that support the various strategies. Here are four examples:

- Transparent assignments, peer review, and Groups tool. In our LMS, we demonstrated the difference between a synchronous breakout room tool and the Groups tool by engaging faculty in peer review of a major assignment description using the transparent assign- 


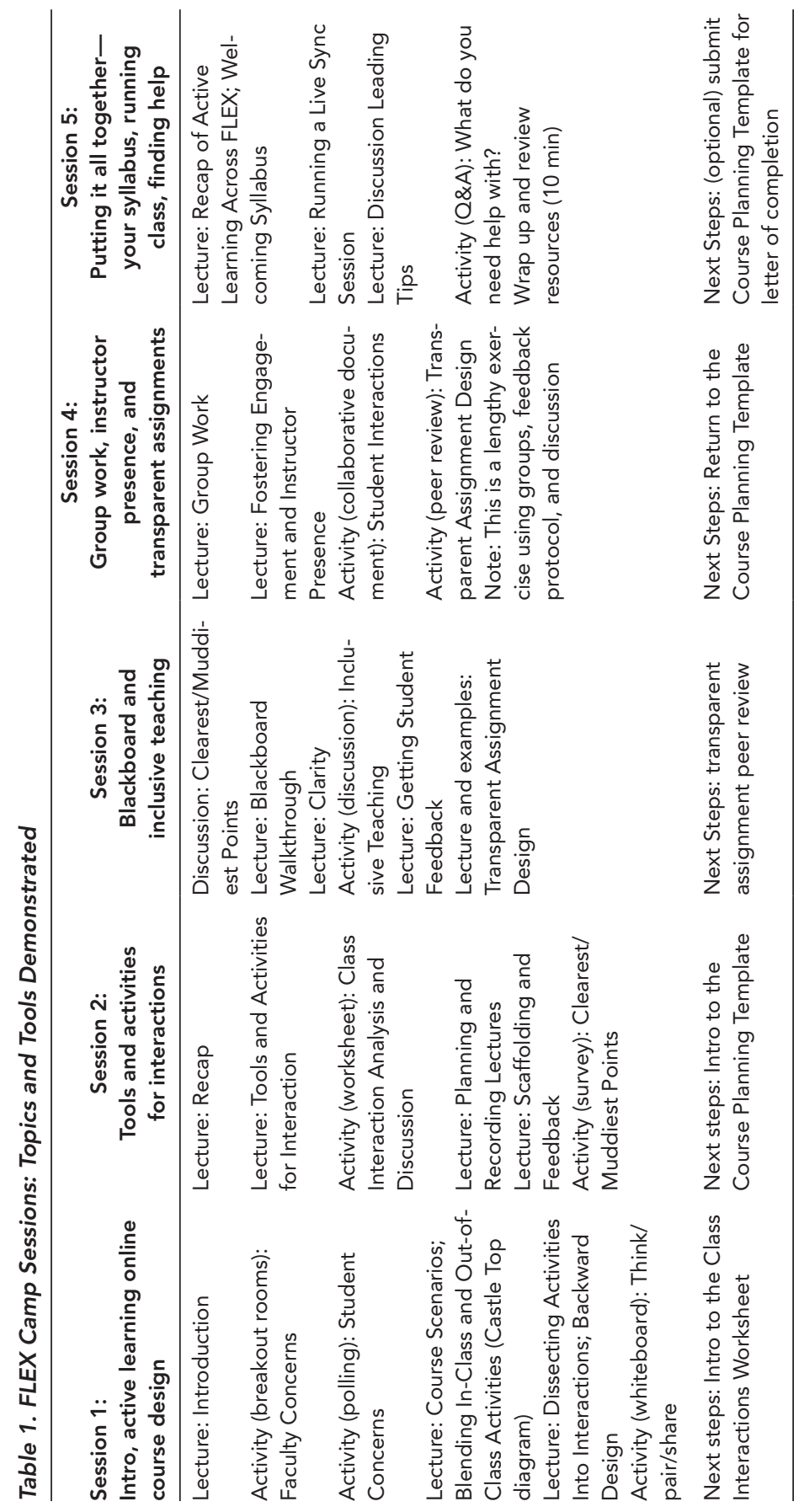

To Improve the Academy • Vol. 39, No. 3 • Spring 2021 
ment design and peer-review process developed by Winkelmes et al. (2016). Faculty not only gained feedback on their assignments, but they also experienced the importance of providing clear instructions, allowing sufficient time for online activities, and managing report-outs.

- Class Interactions Worksheet and using synchronous sessions for work and real-time support. We created a worksheet to help faculty review what they did in their existing in-person class so they could analyze what could be kept, altered, or deleted. We had faculty work through the worksheet during our synchronous time to introduce the idea that they, too, could work in real time with their students. When we started our camps, we were not yet aware that others were also adopting this now popular approach (Bruff, 2020).

- Group work strategies and a collaborative documents tool. Faculty gained exposure to collaborative documents (in our case, Google Docs) by working in small teams to brainstorm strategies for group work.

- Giving help and feedback and the chat function. Using the chat function in synchronous sessions provided insight into ways to provide ongoing help and feedback during a live session. It also demonstrated the importance of managing the chat process.

FLEX Camp allowed faculty to address issues that arose during these exercises in real time. Also, there were many unintended but very helpful lessons. For instance, when our instructions were not clear to participants, they recognized the importance of clarity in instructions, assignments, and other communication with students. When internet connections faltered, they realized the value of testing online tools ahead of an activity. Most of the challenges would be difficult to describe to someone who had not yet experienced an online course.

An added challenge midway through our FLEX Camps was the university's move from projecting a hybrid format for fall to announcing that fall classes would be fully online in mid-July. Fortunately, we had online learning in our sights from the beginning so our FLEX Camp 
program stayed largely the same. We did make some tweaks to a section on active learning techniques because we no longer had to address hybrid approaches. It actually became much easier to talk about teaching once we only had to address the online environment.

\section{Feedback and Gauging Success}

Throughout our programming, we stressed the value of getting feedback from students in the midst of a course rather than relying on endof-course feedback to gauge learning. Therefore, we wanted to model that practice ourselves and encouraged feedback from participants throughout FLEX Camps.

\section{Feedback Tools}

We elicited formal feedback in three ways:

- Brief survey of clearest/muddiest points during camps. This short, two-question survey asked participants what they clearly understood or still had questions about after the second session. Typically, about one-third of participants completed the survey, but it was enough to report back helpful information at the start of the next session.

- Consultation requests. We started receiving requests for individual consultations and special workshops for departments soon after the first FLEX Camps. We viewed these as signs that the program was resonating with faculty, and we improved our processes for tracking and documenting these requests for follow-up.

- End-of-camp survey. This longer survey included matrix questions, using a 4-point scale, for feedback on key activities used during FLEX Camp. Open-ended questions provided opportunities for faculty to reflect on what they learned generally from FLEX Camp, what they learned about themselves as learners, and suggestions for improving the program moving forward. 


\section{Survey Findings}

Of the 250 faculty who completed FLEX Camp, more than $45 \%$ responded to the survey. When asked if they would recommend FLEX Camp to a colleague, $98 \%$ of respondents answered yes. Also, though approximately 70 faculty took us up on the offer to earn a letter of completion, most said they would have attended regardless. Especially given the time commitment of 2.5 days, we view these responses as significant markers of the success of FLEX Camp's content and of our experiential learning approach.

As of this writing, we have had the bandwidth to more deeply analyze surveys for our initial camps (1,2, and 3) and our final camps (6 and 7). The responses have been so similar among the camps that we feel comfortable reporting the answers to two open-ended questions as a single group of responses ( $N=77$ responses).

Survey Question A (open-ended): What was your most useful takeaway from FLEX Camp? We were pleased to see faculty report that we had helped them both with technology and with learning teaching techniques for engaging students. Many stated that their confidence had been boosted and that they felt supported and knew how to find help moving forward. Others mentioned that they appreciated two planning documents we provided, the Class Interactions Worksheet and a Course Planning Template, so that they could continue to map their course once FLEX Camp ended.

Survey Question B (open-ended): What did you learn about yourself as learner? This open-ended question yielded even more evidence that an experiential approach gained traction with our participants. Many faculty valued the opportunity to experience activities from a student's perspective and self-reflected on their own learning style. Others appreciated being part of a cohort of learners or expressed bolstered confidence about handling virtual teaching. Finally, a number of respondents chose to single out transparent assignment design, indicating successful introduction of inclusive teaching practices (transparency) and peer review online. Table 2 cap- 
Table 2. Responses to Two Open-Ended Feedback Survey Questions

\begin{tabular}{|c|c|}
\hline $\begin{array}{l}\text { What was your most } \\
\text { useful takeaway from } \\
\text { FLEX Camp? }\end{array}$ & What did you learn about yourself as learner? \\
\hline Tools (31\%) & $\begin{array}{l}\text { Value of student perspective: As an instructor, I need to view } \\
\text { things from a student's perspective }(25 \%)\end{array}$ \\
\hline $\begin{array}{l}\text { Student engagement } \\
\text { techniques (25\%) }\end{array}$ & Confidence: I have confidence that I can do this (14\%) \\
\hline Confidence boosted (16\%) & $\begin{array}{l}\text { Online teaching: There is a lot I still need to learn about online } \\
\text { teaching }(12 \%)\end{array}$ \\
\hline How to find help (16\%) & $\begin{array}{l}\text { Metacognition: I learn through experiences and enjoy learning } \\
(10 \%)\end{array}$ \\
\hline $\begin{array}{l}\text { Course planning/design } \\
(13 \%)\end{array}$ & $\begin{array}{l}\text { Transparent assignments: I need to make my assignments more } \\
\text { transparent (9\%) }\end{array}$ \\
\hline $\begin{array}{l}\text { Use of the planning tem- } \\
\text { plates }(9 \%)\end{array}$ & $\begin{array}{l}\text { Reassurance: It helped to be with faculty colleagues also seek- } \\
\text { ing help (9\%) }\end{array}$ \\
\hline Assignment design (9\%) & \\
\hline
\end{tabular}

Note. Data from FLEX Camps 1, 2, 3, 6, and $7(N=77)$.

tures, from highest to lowest ranking, the top answers out of 77 unique survey responses to the two open-ended questions.

\section{Recommendations to Colleagues}

While providing faculty with active learning experiences is common in educational development, we believe that an experiential approach works especially well in bringing together technology, pedagogy, and inclusive practices. An experiential approach lets faculty "test drive" tools and teaching approaches together and in real time. This allows faculty to become more aware of and interested in learning about pedagogy.

Here are lessons we learned from our experience with FLEX Camps:

- Gather real-time information on faculty and student concerns, including what they feel they need to know and have time for before 
planning an initiative. Over the summer and into fall semester, we saw shifts in faculty thinking that required us to continuously update camp content to stay relevant.

- Invite the use of chat tools and other forms of immediate feedback while teaching. Faculty reported that chatting kept them engaged. It helped us, as well, recognize and address their needs in the moment. Exercises with Google Docs, short feedback surveys, and presession discussion boards also supported engagement.

- Embrace unintended lessons. Technology will have glitches, and instructions will not work as intended. As frustrating as these can be in the moment, they are often extremely helpful learning experiences for faculty when handled with empathy and understanding. For instance, mishaps opened the door for us to underscore the importance of clarity and adaptability in online teaching.

- Involve your technology support teams. Even though our CTL is aligned organizationally with technology and online learning units, we have found it challenging to stay abreast of changes to the university's technology, including new features on existing platforms and acquisitions of new tools in response to the virtual teaching emergency. Collaborating more fully with the technology support and instructional design teams has been invaluable. It also built faculty trust because we could talk more knowledgeably about the latest tools and/or be able to refer to the correct help resources.

- Invite more opportunities for casual conversation and Q\&A while also providing more in the way of structured templates and resources. We found that faculty appreciated having templates and worksheets to help with course and assignment planning. Some also wanted more time to discuss diversity and inclusive practices with colleagues.

We learned a lot from developing, delivering, and adapting our FLEX Camp format. We pivoted when we had to and were able to work at a scale much greater than before. Thankfully, as we move toward spring 2021, we do not anticipate the same level of crisis as 
before, but we remain unsure of what this will mean for our programming. The challenge we see for ourselves is how to move from the emergent worries about teaching online over this past summer and fall to curiosity about what comes next. What features of online and experiential educational development do we want to retain in the near future and once we can return to an in-person campus?

\section{Biography}

Patricia Dinneen is the Director of Faculty Development in the division of Libraries \& Academic Innovation at The George Washington University. She oversees course design, active learning, and educational improvement programming for faculty and graduate students, addressing in-person and online teaching. Her research efforts focus on faculty motivation and interest in course design and professional development. She holds a Doctorate in Education and a Master's in Distance Education.

\section{Acknowledgments}

My thanks to the FLEX Camp teaching team: Daphna Atias, Gaetano Lotrecchiano, Lauren Tidmore, and Caitlin Savoldelli.

\section{References}

Bruff, D. (2020). Active learning in hybrid and physically distanced classrooms. Vanderbilt Center for Teaching. https://cft.vanderbilt.edu/2020/06/active -learning-in-hybrid-and-socially-distanced-classrooms

Dancy, M. H., \& Henderson, C. (2012). Experiences of new faculty implementing research-based instructional strategies. Proceedings of the 2011 Physics Education Research Conference. https://doi.org/10.1063/1.3680020

Dinneen, P. (2016). Impact of alumni feedback on faculty member attitudes 
about course design: A multi-case study [Unpublished doctoral dissertation]. The George Washington University.

Fink, L. D. (2003). Creating significant learning experiences: An integrated approach to designing college courses. Jossey-Bass.

Hashweh, M. (2014). Pedagogical content knowledge: Lee Shulman. In D. C. Phillips (Ed.), Encyclopedia of educational theory and philosophy (Vol. 2, pp. 598-600). Sage.

Kaplan, S. (2020). Four steps to create a burning platform to motivate change. Inc. https://www.inc.com/soren-kaplan/4-steps-to-create-a-burning-platfo rm-to-motivate-change.html

Koehler, M. (2011, May 11). Using the TPACK image. http://matt-koehler.com /tpack2/using-the-tpack-image/

Kolb, D. A. (1984). Experiential learning: Experience as the source of learning and development. Prentice Hall. https://www.researchgate.net/publicati on/235701029_Experiential_Learning_Experience_As_The_Source_Of_Le arning_And_Development

Rodgers, D. (2018). The TPACK framework explained (with classroom examples). Schoology Exchange. https://www.schoology.com/blog/tpack-fram ework-explained\#: :text=The\%20TPACK\%20framework\%20was\%20intro duced,and\%20Technological\%20Knowledge\%20(TK)

Schein, E. (1996). Kurt Lewin's change theory in the field and in the classroom: Notes toward a model of managed learning. Systems Practice, 9(1), 27-47. https://doi.org/10.1007/BF02173417

Winkelmes, M.-A., Bernacki, M., Butler, J., Zochowski, M., Golanics, J., \& Harriss Weavil, K. (2016). A teaching intervention that increases underserved college students' success. Peer Review, 18(1/2), 31-36.

To Improve the Academy • Vol. 39, No. 3 • Spring 2021 
